\title{
Can Saussure's orangery manuscripts shed new light on biosemiotics?
}

\author{
JUI-PI CHIEN
}

Abstract

In the field of biosemiotics in our time, Ferdinand de Saussure's theory of semiology has been dismissed for its glottocentric, anthropocentric, and dyadic characteristics and as such unsuitable for the said field. Such accusation is symptomatic of an extremely narrow view of Saussure, which ignores the efforts he made in tackling problems concerning the unification of biology (natural sciences) and semiotics (human sciences). A broader view of Saussure, emerging from the newly-discovered orangery manuscripts along with his thought-provoking course lectures, reveals that his epistemology is actually grounded in evolutionary differences and the concept of uniformitarianism. In order to demonstrate the value of his ideas, this paper proceeds through five sections. (1) To begin with, the understandings and misunderstandings of key terms are summarized while seeking to reconcile arbitrary and relatively arbitrary (analogical) modes of consciousness within the network of differences that Saussure proposes in his manuscripts. (2) My study points out how such a network blurs disciplinary or systematic boundaries between language and non-verbal systems and how it might serve as a framework for appreciating true analogies between natural sciences and the science of language. (3) The paradox of analogy, torn between the synchronic and diachronic schemes of time, is discussed. This unravels several strings that have made the functioning of analogy into such a delicate point in Saussure's theory of evolution. (4) The concept of état de langue is made comprehensive in relation to appropriations of Darwinian model and Neo-Darwinian ideas. Saussure's model of evolution explicates the phenomenon of symbiogenesis, which is non-linear, nonadaptive, non-restrictive as regards localities, yet claims certain truths about nature and culture. (5) Finally, my study draws attention to the implications of conceptualizing non-linear evolution within and across systems. There are indeed disparities between Saussure's epistemology and that of biosemiotics: nineteenth-century confused epistemology reoccurred within biosemiotics in its early phase. 
Keywords: biosemiotics, analogy, état de langue, evolutionary differences, uniformitarianism, symbiogenesis, Ferdinand de Saussure

Money has been introduced by convention as a kind of substitute for need or demand; and this is why we call it nomisma, because its value is derived, not from nature but from law (nomos), and can be altered or abolished at will.

- Aristotle (Nicomachean Ethics, Numismatic Museum, Athens)

\section{Introduction}

\subsection{Discursive problematics: Saussure versus Peirce in biosemiotics}

How useful is the semiology of Ferdinand de Saussure for the study of biosemiotics? Since the 1970s, with the organized efforts of certain advocates, the study of biosemiotics has been divided into two strands: biological semiotics and semiotic biology. While advocates of the latter have been pursuing a model for the interpretation of codes and meanings within organic mechanisms, they have also looked back to history in order to ensure the continuity and validity of their scope. Several linguists and biologists in history have been credited with practicing or envisioning biosemiotics, but such efforts have undeniably exposed more stumbling blocks than sound connections. Ferdinand de Saussure has turned out to be one of the main obstacles for such efforts: his theory has been considered to be glottocentric, anthropocentric, and dyadic and as such unsuitable for the study of biological phenomena in general.

In comparison with Peirce's triadic model of sign formation and interpretation, Saussure's theory is criticized for failing on three points: (1) the absence of thirdness, i.e., the interpretant; (2) the arbitrary relation between signifier and signified; (3) the priority of synchronic states over diachronic changes. Another reason why Saussure has been thought to be unsuitable for the study of biosemiotics is that he appeared not to take into account environmental factors (Sebeok 1976: 152; Hoffmeyer 1996: 17-18; Nöth 1998: 337). However inadequate his theory appeared to the demand for a far-reaching model of the living, it should not be so easily dismissed or disposed of (Bouissac 2004: 241, 256; Barbieri 2008: 594-596). Since the 1990s, "meaning" mechanism has been redefined, certain "boundaries" have been extended, and concepts such as "group properties" have been introduced to improve and enhance biosemiotics (Barbieri 2003: 236-237; Kull 1998: 348-349; 2003: 56; Chebanov 1998: 418). Drawing on Saussure's critical thoughts in his orangery manuscripts may shed light on these areas of research. 


\subsection{Textual problematics: orangery manuscripts in relation to other materials}

The standard version of Saussure's ideas derive from Course in General Linguistics (CGL) in which his ideas were presented by editors. A new kind of Saussure, inspiring to biosemiotics, has emerged with the publication of his own writings, Writings in General Linguistics (WGL), the main part of which constitutes the so-called "orangery manuscripts." This postponed publication gives rise to the question whether the ideas that have emerged from standard readings of CGL really do justice to Saussure's innovative - even revolutionary - theory. For Saussure scholars like Roy Harris (1993) and Simon Bouquet (1997), the immediate light that these manuscripts brings to the world is to prove that Saussure's colleagues, Charles Bally and Albert Sechehaye, have misrepresented his ideas and imposed their own on him (Harris 2002; De Saussure 2006: xvi). It is natural to make such hasty judgment since there is indeed a discrepancy between CGL where Saussure's ideas were put into succinct and systematic categories and the manuscripts where Saussure questions himself and his contemporaries. This reflects a standard problem in the discovery of new materials: there is a temptation to "discover" hidden aspects ignored by established schools of thought. Thus, before glorifying the presumed greater authenticity of these recently found in the manuscripts, we should consider the actual discrepancies between these two groups of materials.

Saussure wrote the major portion of orangery manuscripts, which he entitled as "Dual Essence of Language," shortly after his three inaugural lectures in 1891 (Engler 2004: 48). Bally and Sechehaye, on the other hand edited, CGL on the basis of notes made by students attending Saussure's courses on general linguistics and published it in 1916, three years after Saussure's death. Bally and Sechehaye ignored inconsistencies between students' notes and Saussure's writings and concentrated on what they believed were the most definitive distinguishing features of the Geneva school (Amsterdamska 1987). Actually, Saussure insisted that one should never publish writings before they have reached their definitive form (Engler 2004: 47-48). As he was constantly experimenting with his thoughts, it is hardly surprising to find constant questionings and self-criticisms in the manuscripts - which eventually caused the manuscripts to be left uncompleted when he suddenly passed away in 1913. Nevertheless, the orangery manuscripts should be thought of as more original material than CGL.

Until the discovery of the manuscripts, scholars relied on the critical edition in four volumes in which the editor Rudolf Engler lays out corresponding passages from editions of CGL, students' notes, and Saussure's personal notes on six parallel columns. After examining their textual variations closely, Engler 
does not accuse Bally and Sechehaye of professional misconduct, but instead draws attention to the nature of Saussure's writings. First, he indicates that Saussure constantly renewed (or rephrased) his ideas and had the capacity to develop his ideas in all directions without contradicting himself. Second, it is only human that one's words in written form and in oral presentation sometimes contradict each other, which certainly has happened to Saussure (De Saussure 1967: Preface). Based on these observations, we can argue that there has actually been only one Saussure: we always find the same group of key concepts whatever source material we start from. Comparing the texts with one another, we can cast light on Saussure's rephrasings, questionings, and criticisms. The multiple sources may well be synthesized into a more or less unified whole where key concepts can be related to relevant frames of reference. Therefore, though this study introduces a newly-discovered material into biosemiotics, it does not mean that there is a completely new Saussure awaiting us - all materials that have been made available up to the present are equally valid when discussing his method. However, redefining the theoretical framework of biosemiotics in the light of the newly available materials may help us appreciate the effectiveness of his conceptual tools.

\subsection{Methodological problematics: The significance of genuine and overall change within a system}

Many of the misunderstandings of Saussure's ideas can be attributed to the misuse of the word "state" and its adjectival form "static" in translations and commentaries. The way these words have been used gives the impression that Saussure thought language should be studied as if it were in a permanent state, not subject to changes.

However, according to the manuscripts, the diachronic dimension of language is every bit as important as the synchronic, and the study of the latter in its own right, manifested in the form of état de langue (abbreviated as EDL hereafter), facilitates exploring the former (Saussure 2006: 7).

On top of the false impression of EDL, the Saussurean notion of "arbitrariness" has been much exploited: it is either criticized as the lack of natural links between signifier and signified or overgeneralized as the whole of his system (Jakobson 1990 [1966]). In his third course lecture, a major portion of which touches upon la langue (the rule or law summarized from different languages), he called his students' attention immediately to the matter of choice and $a$ posteriori connections between signifier and signified. For him, they not only shape the learning and speaking of a language but also explain the fact that every language (or system) is different in its own right. By employing the notion of arbitrariness to define his idea of signs, he was able to defend his system 
against the philosophy that there is a shared and predetermined origin of languages. Furthermore, within a specific system, he saw that arbitrariness functions in a solitary and limited fashion: it gives rise to the making of terms which cannot be related to (or associated with) others (il fait appel à rien; Saussure 1967: 86). The outreaching and sociable force en vivant goes to relative arbitrariness (analogy), which is able to reproduce shared units in different terms. Arbitrary and relatively arbitrary states of mind make up for a system - the former, though idealized, serves as a point of departure, while the latter (analogy) explains the status quo. Although it has been generally conceived that the latter sets limits to the former, they both are governed by the law of generating a posteriori, artificial, and reworkable connections (EDLs) within one sign entity and across many others within a system.

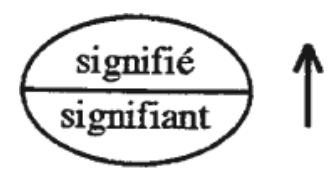

Figure 1. The schema of sign (Saussure 1993: 139)

Such seemingly contradictory but actually compatible states can be made comprehensive by looking into Emile Constantin's notes (taken for the third course lecture) along with Saussure's diagrams and writings. At the beginning of his lecture on the nature of linguistic sign (dated May 2, 1911), Saussure declared that he would reject approaches to la langue that do not start from the two-term structure, i.e., a form and a meaning (1967: 150; 1993: 75a; Figure 1). However, as he gradually elaborated on it along with his critical tools, he indicated at one point that such structure (or schema) is not the "starting point" (n'est doc pas initial) in the study of la langue at all — the schema should be made into play and to address phenomena of all kinds beyond the formation of vocabulary only (ce schema peut entrer en jeu; il s'agit de n'importe quoi [dated July 4, 1911]; 1967: 264; 1993: 140a). Looking further back in time, as revealed in his orangery manuscripts (1891), we find that already at this early stage he has criticized the structure (Figure 1) as something that is "entirely rough" and shows a "profound misconception" of la langue (2006: 22, 24). He then proposed "a range of possible forms and possible meanings," which interact through their distinctions but in no way correspond to each other, as a better representation of signs (Figure 2).

For unknown reasons, Saussure propagated the self-criticized structure (and schema; see Figure 1) to his students but stored most of his ramifications on the network of differences for his own - the "true thoughts" (pensée intime; see 
General difference of meanings

(only existsin relation to forms)

\section{General difference of forms \\ (only exists in relation to meanings)}

Figure 2. Saussure's proposed approach to the study of signs in his orangery manuscripts (2006: 24)

Figure 2) that he cherished and used as the starting point of his manuscripts appear only in elliptical lines towards the end of his third course lecture (2006: 59; 1993: 140a-143a). Moreover, in his orangery manuscripts, he had already conceptualized the functioning of a system in accordance with the idea of a "complicated game leading to a final balance" (les différences qui résultent $d u$ jeu compliqué et de l'équilibre final; 2006: 43). Such a game generates networks among signs without limit, starting point or any fixed point. It not only enables signs to absorb and locate new ideas at any time but also serves to change the boundary of general meaning from time to time (2006: 22, 50-51, 60). Despite having introduced such prospect into the actual functioning of his system, he still affirmed that the whole thing is the "result" of the schema that he has defined and criticized (2006: 43). With such a model of mind that generates and learns from endless differentiations, Saussure annuls binary oppositions generally made between literal and figurative meanings, physical words and spiritual meanings, signs inside and outside consciousness, and above all, the philosophy (or metaphysics) of language since the eighteenth century (2006: 47-51, $56,59,64)$.

Before having access to the manuscripts, one could even suspect that EDL is simply a term void of precise content (Da Camara 1995: 128). This, however, is just another misunderstanding. Already in his inaugural lectures Saussure warned about defining EDL in terms of concrete but "loose markers," such as historical period, language, dialect, the borders of a country or geographical area (Saussure 2006: 111). The manuscripts reveal how he then sought to define EDL in more abstract terms in an attempt to develop it into a working tool for theorizing differentiations, multiplications, fragmentations, and discontinuities in the continuous currents of languages. He was planning a drastic move away from contemporary received notions about language. Examining his inaugural lectures (1891), orangery manuscripts (1891), students' notes (1907-1911), and CGL (1916) together allows us to argue that EDL is as vigorous and sophisticated a term as analogical creation, negative categorization, and general difference. With this group of terms, Saussure has explored the changing state of human consciousness as it develops new forms of verbs and expands semantic networks. The kind of change he conceptualizes is not to be 
measured by the variation of forms on the surface but should rather be considered as a system within which the boundary of general meaning functions across and beyond several EDLs. We can now explore how, as an alternative to crude evolutionism, these concepts can function in analyzing genuine and overall system change.

\section{The study of language and non-verbal systems}

\subsection{False and true analogies with natural sciences}

For Saussure, the object of linguistics had not been precisely and consistently circumscribed in the way in the natural sciences of his time the objects of study were "readily defined" right at the beginning of investigations (Saussure 2006: $5,44)$. In his inaugural lectures, he criticized that natural sciences had misguided the study of languages, leading to the introduction of several master tropes that imply parallel patterns of life and death among languages, plants, and organisms. Such analogies fail to do justice to human will, consciousness, and intelligence (2006: 100-101). The study of the universal laws of languages and other related mental processes should be grounded upon the study of actual use of individual languages across time and space. After the unique and independent laws of languages have been abstracted, it will then be "of occasional and incidental importance" to discuss how linguistics can "shed light" on other objects of inquiry (2006: 94). He stated his goal and purpose explicitly as follows:

Does the phenomenon of language merit study in its own right, whether in its various manifestations or in the general underlying rules which can only be inferred from specific forms? This, to be crystal clear, is the fundamental question today for the science of language. Can language (le langage) or the language system (la langue) qualify as an object intrinsically requiring study? That is the question. (Saussure 2006: 94-95)

These questions constitute the raison d'être of his inquiry. Throughout the inaugural lectures, Saussure uses the two terms, langage and langue, in both figurative and abstract senses. Langage can be the "manifestation" of human speech activity (la parole articulée) and the "driving force" (le plus formidable engin) behind the collective action of speaking (2006: 95), while langue is in one sense certain natural language shared by a community and in another a set of rules which binds speakers together within the community. These four aspects of study draw materials exclusively from what speaking subjects have articulated within and across communities. The concrete objects that these articulations refer to in subjects' actual living environments cannot find a place 
within his scope of linguistics (2006: 98-99). Furthermore, by declaring that rules are to be inferred from forms, he distinguishes linguistic inquiry from other fields of study on the basis of induction. It is a procedure that starts from diverse forms and ends up discovering the most abstract rule that governs them all. Such a procedure overturns what philologists and natural philosophers practiced at the time: they were criticized for having deduced (or made up) forms or examples according to certain hypotheses, imagined rules, or written records $(2006$ : 87-88, 96). Defining language as an activity that is governed by its own rules, Saussure draws our attention to what goes on inside human brains in their collective and complicated fashion.

To identify and conceptualize the link (or "point of connection") between forms and meanings is an essential task on Saussure's agenda (2006: 4). Although he opposes borrowing metaphors from natural sciences and demands that linguistics should develop its own concepts, he does indulge in such parallels in his manuscripts: analogies with objects in natural sciences are not always false. The ways they function inspire Saussure to refine the relationship between forms and meanings as three stages: (1) association, (2) classification and (3) differentiation (2006: 3-6; 42-43). First, he draws a parallel between the chemical components of air and the dual essence of linguistic entity. The way air is a mixture (mélange) of two heterogeneous elements, nitrogen and oxygen, is perfectly analogous to the formation of a sign. However diverse these two elements may be, they both belong to the same order or domain. Linguists are advised not to take forms and meanings as an "odd combination" of physical and psychological domains. It is only within the psychological that the seemingly distinct forms and meanings can work together.

However, linguistic entity and chemical mixture differ from each other in that the former cannot be divided like the latter. The chemical law allows the classification of nitrogen and oxygen into separate categories, self-sufficient and homogeneous, but it is not so with linguistic entities. Forms and meanings cannot be detached from each other, not to mention segmenting forms (words) into letters. The link between them is made possible by their common domain and further enhanced by belonging to the same grammatical category. A linguistic entity cannot function independently from other entities because they all together form a system. On its own, the entity is empty, deprived of its innate reality, but it becomes activated through the sum of differences that emerge through its connecting with other entities. These differences are constantly multiplying and changing, but they may lead to a temporary balance within the system. At the last stage of conceptualization, however, a chemical mixture serves as an extreme contrast with linguistic entity: the former is by itself informative enough for scientists to generate knowledge, while the latter is completely empty unless linguists observe it within a system made up by different entities and categories. Thus, though Saussure is critical about apply- 
ing concepts and metaphors derived from natural sciences to linguistics, such procedures actually constitute an indispensable part of his manuscripts as he discusses the dual essence of linguistic objects.

\subsection{The coexistence of linguistic system with non-linguistic systems in semiology}

The main thing that Saussure benefited from in seeking parallels with the natural sciences was classification and categorization, i.e., bringing order to the objects of inquiry. However, regarding the extension of laws and universal processes, i.e., la langue, into other sciences, he presented only vague ideas. In his inaugural lectures, he declared that there is a major divergence between linguistics and natural sciences, insisting that they cannot go together since the former follows the historical and the latter physical laws (Saussure 2006: 97 98). Nevertheless, as he gets down to reflecting on the more embracing science of semiology, such strict distinction retreats to the background. His tone becomes so tolerant that we wonder whether his targeted objects can also take part in semiology. He wrote as follows:

Whatever differentiates [la] langue from other semiological systems must be regarded as its least important aspect ... Thus, when the movement of the vocal apparatus is considered first ... this cannot be of great importance, for it is not semiological, since some systems do not use the vocal apparatus. At the same time, in elements that are common to $[$ la $]$ langue and to other semiological systems, we can see that what might be called the original contract, the initial convention, is of less importance. (Saussure 2006: 201-202; 2002: 288)

What he advocates here is the appreciation of similarities (or analogous relationships) among different kinds of systems from the viewpoint of semiology. The faculty of speaking is not the only means of generating signs and it should not be used to isolate the linguistic system from others - we should perceive similarities at a deeper level. Saussure implies that we do not take seriously enough "the original contract," i.e., the fundamental way of associating forms with meanings or one system with another. The semiological system blurs boundaries and distinctions and it changes just like linguistic systems do. Certain fundamental features of semiological systems offer an index to the way many other systems function. These ideas can help us in our need conceptualize analogous relationships between biological and linguistic systems. The way that Saussure takes plants, animals, organisms, and chemicals as isolated and self-evident entities was constrained by the physical law of objects at the time, but his semiology is quite promising as "linguistic forces" (or the role of vocal apparatus) no more have a priority among living systems (1959: 17). 


\section{Conceptualization of a linguistic system}

\subsection{Analogical reasoning and language change}

In order to better define the fundamental features of a linguistic system, Saussure brought forward a rather unconventional perspective of time. The traditional perspective gave the impression of a Language in History (Langue dans l'Histoire), within which we give distinctive labels to successive periods (for example, from Latin to French; Saussure 2006: 110). However, for Saussure, what matters is more about life than death, and the target issue should be rephrased as the history of language (l'histoire de la langue; 2006: 98). Situating la langue within such a long duration, he aimed to pay equal attention to the analytical and functional aspects of language change. These changes are by definition not the outcome of actual contacts between languages but rather a revelation of functional similarities shared between them (in this sense, Latin is French). These similarities can be of two kinds: phonetic shifts and analogical transformations (2006: 106). The former follow an absolutely arbitrary rule to produce diversified forms on the surface, while the latter manifest human consciousness, intelligence, and intention behind the phenomenon of changing forms. With the guidance of the latter, in particular, speaking subjects can learn grammatical and meaningful forms and linguists predict new forms and restore old ones (2006: 106-107, 109). Analogical reasoning exemplifies not just a tool for learning but also a discovery procedure: what has been learned can be associated with what is potentially to be learned (Itkonen 2005). The vista that Saussure opened onto language as a living system is the co-existence of both exact and approximate truths. His approach is based upon certain rules (or laws) that strictly define the system as an object (the way most natural scientists have adopted), but it also considers deviations that from time to time go beyond the stricture of laws - in this sense Saussure and Darwin mutually shared the concern about conceptualizing changes or mutations in history.

One of the laws that Saussure offered to explain never-ending transformations in languages is homology, made up by an infinite series of analogy $(\mathrm{A}$ : $\mathrm{B}=\mathrm{C}$ : $\mathrm{D}$, etc.). As he indicated in his second inaugural lecture (1891), analogical reasoning is so logical and consistent that grammatical and meaningful considerations have to overrule phonetic and material inconsistencies. Otherwise, false analogies can be generated such as punir: punirai = venir: venirai (in fact: viendrai), which means that the two verbs actually do not share the same grammatical category (Saussure 2006: 107). Following the analogical thinking and reasoning process, the association of the form and meaning of $\mathrm{C}$ itself is always the point of departure. However, from here on the process is preconditioned and activated by the knowledge (or memory) of the pattern 
presented in the relationship between A and B. The parallel between A: B and $\mathrm{C}$ : D leads speaking subjects to creating $\mathrm{D}$ by imitating $\mathrm{B}$. The end product $\mathrm{D}$ emerges, so to say, through the collaboration with A, B, and C: its life is given but constrained by the forms and meanings of the others and the way they are related. In tune with such a precise mechanism, it is not likely to come up with a deviated form (anomaly) at $\mathrm{D}$. The reason why deviation still happens from time to time can be attributed to a confusion (or the uncertainty) of rules, categories or perspectives, i.e., a wrong way of relating $\mathrm{C}$ to $\mathrm{A}$.

Following the standard formula, we can substitute A and B for a lot more pairs of different meanings, but it always comes down to their grammatical type shared with $\mathrm{C}$ to delineate the boundary of accepted comparisons. The substitution of A and B for different pairs is governed by analogical reasoning as well. Therefore, analogical thinking should be able to function both horizontally and vertically (across time and space). It serves to generate grammatical forms and to create unexpectedly (or unintentionally) new forms (1993: 115a), even though the one-dimensional formula is the only way to demonstrate results on two different axes. In his 1891 inaugural lectures, Saussure pointed out such movements in two directions (2006: 107). We still find similar reasoning in CGL as follows:

An analogical form is a form made on the model of one or more other forms in accordance with a definite rule (1959: 161) . . . Any creation must be preceded by an unconscious comparison of the materials deposited in the storehouse of language, where productive forms are arranged according to their syntagmatic and associative relations. (Saussure 1959: 165) ${ }^{1}$

Despite the fact that Saussure counted on analogy to explain the "absolute continuity" of language in time ("Paradigmatic" and "diachronic" relations are alternative terms to "associative" relation, the three of which explain the dimension of time with subtle distinctions), he was reluctant to conclude that "analogy" is part of "language change" in history in his inaugural lectures (2006: 111). On other occasions, such as his second course lecture, he thought it "embarrassing" to have suggested "the realm of the diachronic" as soon as he touched upon the seemingly change to which analogy can give rise. Instead of dismissing the possibility of finding a place for analogy in diachrony, he circumvented the problem by saying that analogy is "a very delicate point in the distinction between synchronic and diachronic." However, as it shows in another student's notes taken for the same course, Saussure admitted that he has contradicted himself in introducing analogy into the diachronic. Moreover, the "delicate point" he would like to make is that analogy can find no other realm than the synchronic as the latter offers the former an "état de la langue" (1968: 390; abbreviated as EDL in this paper). 
In addition to synchrony, Saussure considered EDL as another key concept in the delineation of a proper context for the functioning of analogy. Whereas EDL is thought of in terms of relatively short units of time (which can be a stage, a period, an hour, or a second, i.e., isolated and singular micro units), diachrony governs some such units at a macro level. However, diachrony can be easily confused with the conventional notion of history that adheres to the idea of an "imperceptible transition" or a "sudden emergence" of one language from another (2006: 110). For Saussure, there are no such presuppositions as transitions, connections, and even contacts: he preferred to apply the notion of analogy in observing both micro and macro events. Therefore, what he meant with the absolute continuity of language in time is not about rationalizing gaps but forming and applying a method or perspective consistently, which is by definition analogical thinking.

The suspicion over whether analogy can be effective in diachrony appears far more revealing in Saussure's discussion on evolution theory. There were several aspects on the Darwinian agenda at the time. Saussure spoke cynically against the aspect that advocates sound transitions and the shared origin among species (2006: 110). The idea of seamless continuity conveyed in the theory, natura non facit saltus (Nature never makes a leap), was against his sense of history and the way he defined diachrony. Thus, he picked up the theory of "the survival of the fittest" to examine whether the functioning of analogy can fit in. He relates his critical tool to evolution as follows:

[I]t is evident that analogy by itself could not be a force in evolution, and that the constant substitution of new forms for old ones is one of the most striking features in the transformation of languages. Each time a new formation becomes definitely installed and eliminates its rival, something is actually created and something else abandoned, with the result that analogy occupies a preponderant place in the theory of evolution. (Saussure 1959: 169)

This brief observation reveals that analogies emerge from the dynamic relations between EDL and diachrony. Since EDL offers the base and context for analogy, a new form always occurs within the boundary it delineates. However, the force that gives rise to such phenomenon lies outside the form itself, which is actually a congregation of surrounding terms of the same grammatical category. In an ideal sense, EDL encircles a safe and faithful boundary for the force to generate new forms, with the result that there is no distinction between old and new. Such a distinction (or tension) only becomes apparent when analogy functions between irrelevant EDLs. Therefore, the phenomena of substitution, elimination, and installation of forms are observed between and across EDLs. In the situation where analogy and EDL are in harmony (in the formula, for example), the competing forces are hidden. However, as soon as analogy 
extends its power to the diachronic, it starts to take the upper hand to govern the latter and makes the decision whether two similar forms in their respective EDLs can coexist for some time or the new should supplant the old (honos honorem-honor [a rival species]).

The effect that analogy exerts on several EDLs in diachrony is more than a confusion of categories - it can be a veritable coup d'état that modifies the synchronic law completely. As Saussure probed into the interactions between synchronic and diachronic facts in his third course lecture - which he termed the second crossroads in linguistics; the first ones being the distinctions between language (langue) and speech (parole) - he came to the conclusion that the nature of "law" is split between synchrony and diachrony: the synchronic law is, in comparison with the diachronic law, rather vulnerable and subject to the imperative force from the latter. He formulated the divided senses of law as follows:

A synchronic law expresses an existing order. This law captures a state of affairs, an arrangement ... The arrangement is precarious since it is not imperative, it exists for as long as it is allowed to exist. The [synchronic] law does not preserve state of affairs (état de choses) against a change ... [It] is at the mercy of any diachronic law [accident] that would alter it. (Saussure 1993: 118a; 1967: 206, 207)

It seems Saussure was undermining the base (or the point of departure) of his whole project - the synchronic and EDL offer the ideal home for analogy. However, there is no denying that EDLs, in their extreme forms, only pertain to weeks or months (2006: 101). From the perspective of the diachronic law, they are seen deprived of the validity of extensive duration, and thus the internal bound within analogical formations is always endangered. The bound becomes loose, or rather, is subject to rearrangement (another order) when it is observed from the standpoint of diachronical macro events. Basing on these bifurcated senses of law, Saussure also drew our attention to the distinctions between an actual body and the shadow it projects on a surface. The paradox of the synchronic facts was thus further enhanced: they are projections whose formation is dependent upon their bodies (diachronic facts; historical realities) but whose survival is completely dependent on their going along with something else (1993: 123a). Observing that they actually go beyond the measurement of material, physical, and historical truths (for they are like shadows, ghosts, and phantoms; Figure 3), Saussure proposed that, for linguists, it takes other fields of knowledge to find out how the projection can be made, optics and mathematics, for example. As a very delicate point in the distinction between the synchronic and the diachronic - the point that structures the synchronic and the diachronic as perpendicular planes to each other - analogy is, 


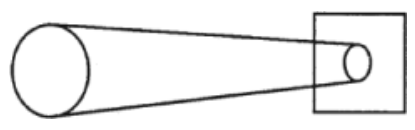

Figure 3. The synchronic fact is a projection of the diachronic fact (1993: 123)

in a paradoxical fashion, something that is the one and the other: both constative and imperative, both lasting and fortuitous, both material and non-material.

\subsection{EDL(s) as the "central object" of linguistics}

Such paradox also applies to the conceptualization of EDL: it can be in plural form, indicating explicitly different stages of la langue in history; it can be in singular form, manifesting a certain mental capacity (such as analogical thinking) that constantly generates new relationships between forms and meanings. The two relate reciprocally to each other with regard to their occurrences in time, but Saussure insisted on keeping them conceptually apart as he reclaimed his object of study towards the end of his manuscripts. He wrote:

The examination of a sequence of states offers the linguist one central object. This object does not enter into a straightforward, marked opposition with the preceding one, but into a relationship of radical disparity, which necessarily precludes all comparison, opening up a new order of ideas which can in no way exist in relation to a given $[E D L]$. (Saussure 2006: 59)

As he continued to elaborate on this point in his first course lecture, he made the point that EDL is at bottom social and psychological (1996: 2). Meanwhile, he would like to take this notion to put forward a different sense of history and evolution - EDL is what speaking subjects have "immediate sense and control of," "a movement in time without worrying about whether it is a development, [a movement] forward or backward" (1996: 27-28). He valued the power of creating new orders to the extent that he denounced the need of EDL in its plural form: speaking subjects can have forgotten or ignored EDLs in history but they are still able to coin new forms in their environments (1996: 61 ). On the other hand, EDL is also the power to negate (involving interpreting and decomposing entities or units), with which speaking subjects not only collocate EDLs but also restructure the links between forms and meanings across EDLs (90-91). The benefit of such mental work is to build up multiplying networks without the limitation of one's immediate condition or environment:

$[\mathrm{U}]$ nderstanding the purely negative, purely differential, essence of each of the elements of language that we hastily assume to exist is a never-ending task. Not one of 
them, however ordered, possesses this supposed existence - although admittedly we may have to recognize that without this invention (cette fiction) the mind would be literally incapable of dealing with such a mass of differences, with no positive, solid reference point at any place or time ... these differences which make up the whole of [la langue] would represent nothing. (De Saussure 2006: 42-43)

EDL in its most abstract form is not any tangible entity but an abstraction that Saussure formed and utilized for introducing the value of "new combinations" or "sudden constructions" into the evolution of a linguistic (or any other living and semiological) system (1996: 63, 90-91). These non-ceasing changes and growing differences that have no hierarchical orders contribute to the increase of novel relationships between signs and the extension of boundaries between grammatical categories (2006: 60). Such deep and overall change of a system is not measured by the presence (appearance) or absence (disappearance) of specific signs since they can recur any time in history. Signs in general absorb and elaborate on the value that has been defined by certain stages or categories. However, a complete change within a system is not to continue the elaboration — it simply alters, ignores or abolishes some such previously-defined value.

\section{Saussurean epistemology of evolution}

The validity of a tool for the observation of life within a long period has been a matter of concern to scientists and philosophers. This explains why the Darwinian term, species, is still much favored in our time: it not only serves as an analytical unit for taxonomy but also facilitates cross-scientific diachronic studies at multiple levels (McCauley 2007). Somewhat in the manner of how the notion of species serves scientific and philosophical purposes, EDL is a concept that is reduced but capable of extending its validity to as many language phenomena as possible. Recent studies on gene-language co-evolution (including the hypothetical forms of protolanguage), Paleolithic continuity theory, and glossogenetic processes point to the importance of culture and society in the process of language change: (1) languages evolve as humans within their communities, producing a range of more or less structured and lasting combinations of linguistic units; (2) languages spread and change along with the migrations of Homo sapiens (Hurford 1992, 2007; Danesi 2004; Alinei 2006; Katz 2008). They show that we cannot draw an encompassing picture of language evolution if we simply adhere to the idea of linear development of language. Part of the problem is that - apart from the misappropriation of certain metaphors and thereby confused epistemologies - Darwinism did not really have a sufficiently revolutionary impact upon linguists in the nineteenth century (Nerlich 1989; Auroux 2007; Klippi 2007). Saussure's notion of EDL 
was overshadowed by the efforts of mapping the idea of species, organs, and natural selection onto language variations. Thus, our task is to explore: (1) Saussure's criticism of the fallacious applications of Darwinian assumptions to linguistics; (2) how Saussure's uncompromising approach is compatible with the idea of "symbiogenesis," i.e., non-linear and non-adaptive evolution (Gontier 2006); (3) how EDL helps reveal greater truths about nature and culture.

\subsection{The unity and universality of object}

Discussing the problems different sciences faced in the nineteenth century, August Schleicher (1821-1868) suggested that the study of languages was in a more advantageous position than the study of the development of species: it is rich in written records from the ancient to the contemporary which can be used to confirm linguists' observations, whereas natural scientists base their work on less well preserved and randomly surviving specimens or remains of animals and plants (Schleicher 1983: 42-44). Schleicher only considered the quantitative differences of objects, i.e., their degrees of completeness, and did not explore their qualitative or "specific" differences — which he thought are not really essential (1983: 45). He affirmed that parallels can be found between the gradual variations of languages and species: (1) "languages are organisms of nature; they have never been directed by the will of man . . . they [grow] old and [die] out" (1983: 20-21); (2) "for the terms species, sub-species, variety, we substitute the words language, dialect, patois" (1983: 47-48). Most of all, he believed that viewing species and languages as concrete entities can make a significant breakthrough in conceptualizing modern science. He argued for the prospect as follows:

The tendency of modern thought is undeniably towards monism. Dualism [binary oppositions] . . . is no longer a firm ground to stand upon, if we wish to survey the field of modern science ... It is now more than ever necessary to occupy oneself with the most minute special study of the object, without thinking at all of a systematic upbuilding of the whole ... The importance which the observation of facts has acquired for science in general, but more especially for natural sciences, is the unavoidable result of the monistic principle, which does not look for anything behind the things, but looks upon the object as identical with its form or appearance. Observation is the foundation of modern knowledge; nothing else is acceptable but the necessary conclusions arrived at through that channel. (Schleicher 1983: 23-24, 25-26)

Schleicher shifted the focus of scientific research from its previous paradigm governed by Linné's Systema Nature to the minute details of objects. Nevertheless, he was still constrained by the idea that languages as well as living 
beings should be specified and put into categories according to their appearances. Without looking into how Darwinian terms serve to implicate the observation of nuances that are likely to divide languages from species, Schleicher simply kept on repeating the Darwinian jargon and making baffling statements - he failed to justify how "widely different" speech is from animal and vegetable kingdoms (1983: 64-65). He illustrated the origin and divergences of language families in accordance with Darwin's tree diagram, but it is questionable how his bringing together of terms used in different domains could bring about a new approach to the conceptualization of language diversities. This problem was tackled in a cynical tone in Saussure's manuscripts and notes. He pointed up the dilemma as follows:

If we were invited first to determine the chemical classification of a sheet of iron, gold, or copper, and then the zoological species of a horse, cow, or sheep, these would be two easy tasks. But if we were asked to determine what "species" is represented by the odd combination of an iron plaque attached to a horse, a gold plate on a cow, or a sheep adorned with something copper, we would exclaim that the task was absurd. The linguist has to realize that it is precisely this absurd task that faces him right from the very outset. (Saussure 2006: 3)

Saussure's criticism reveals that a new object of study is not likely to emerge if linguists simply divide and combine singular and isolated substances - such efforts trivialize their observations rather than bringing unity to what is still waiting to be defined. What should be unified is linguists' viewpoint: a perspective that forces them to look straight into the actual functioning of languages and to form a holistic and comprehensive view of diversities. Furthermore, it is futile to explore whether languages are like species or chemical elements, or how many functions (or capabilities) they have in parallel with functions in organs or compounds. To break up languages in the same way in which anatomists, physiologists, and chemists have done in their respective fields of study simply shies away from exploring what actually governs the production of languages. According to Saussure, unlike in the field of natural history, in the development of languages death has no dominion. In his notes, he pinpointed the sharp distinction between his and naturalists' viewpoints:

In an organized being a function can die without the organ dying. Even a corpse still has its organs, which are the material of anatomical science. In the word, there is absolutely nothing anatomical, i.e., no difference in parts based on a relationship between the function and the part which carried out this function. There is only a sequence of acoustic productions which are perfectly similar to one another, in that lung [poumon] and foot [pied] are all the same in the word. [This is the] Principle of Identical capacity. (Saussure 2006: 77) 
Saussure takes it as an urgent task to unify and universalize the study of the functions for the production of words and parts of speech: it should not just pertain to certain language families or specific members of a language family but all languages. In contrast, naturalists observe various specific functions when they shift from organ to organ. Linguists who try to adapt such an approach not only become confused about the right path of linguistics but also eliminate its metacritical power expected to explicate non-linguistic systems as well. In order to avoid indiscriminate adoption of naturalists' terms and the implications of the analogy with bodily organic functions, Saussure offers another term, "an instance of pure consciousness" (un fait de conscience pure), to distinguish the evolution of languages from that among animals and plants (2006: 4). As a challenge to pseudo-Darwinian attempts at identifying origins, permanent features, functions, and stages of development, the Saussurean idea of looking into human consciousness initiates a new linguistic epistemology that is a step further forward from indiscriminate adaptations of natural history (2006: 110). It is a way of observing phenomena in a way that gives rise to EDL as the abstract yet complete object of linguistics:

This is not a trivial observation: the phenomenon under study exists only in the presence of those phenomena that are in contrast to it ... [F] or any linguistic term, which since ... cannot exist, even fleetingly, in its own right and independently of its contrast with others, and which cannot be anything greater than an approximate encapsulation of the sum of differences at work. Only these differences exist; which means that the whole object of the science of language finds itself in the realm of relativity. (Saussure 2006: 42-43)

As a new object to be observed in linguistics and evolution (rather than the evolution of languages in naturalists' terms), EDL has as its aim the discovering of contrasts between entities: it does not aim at reconstructing specific needs, functions, organs, and origins on the basis of pieces of evidence - as in models inspired by the supposed analogies between anatomy and philology - rather, it is highly charged with the interest in establishing ever more links and differences between such pieces of evidence. Furthermore, EDL overcomes the problem that approaches on the lines of Darwinian tree diagram face regarding linguistic evidence. While in the latter the notion of languages evolving on certain teleological lines, in which the continuation or disappearance of certain features is a matter of life and death, often leading into ignoring pieces of evidence that do not fit this model (Gontier 2006: 211-213), in the study of EDL there is no need to ignore undesirable facts and construct perfected entities of language development. It constantly jumps between at times seemingly unrelated linguistic entities in its study of hybridizations and mutations that emerge out of its repertoire of differences. Moreover, EDL as an analytical tool 
pays equal attention to ontogenesis and phylogenesis: children can make errors while they are learning conjugations; different natural languages cross-fertilize by exchanging units of words. On the basis of such cycling and recycling of pieces, EDL also shuns the strict distinctions made between genotypes and phenotypes in the Modern Synthesis, in which the former are taken as the groundwork while the latter are given more attention as regards their variations in phylogenic environments (Gontier 2006: 11-12). In comparison with the two standard evolutionary models, the unity and universality of EDL lies in the fact that it brings together pieces of evidence found from the past and the present - the bottom and the surface, the near and the distant — for our scrutiny here and now.

\subsection{Intercourses, innovating waves, and concordances}

Saussure's ambition of challenging natural history and the notion of linear evolution is manifested in his third course lecture as he extended his discussion on the unity of linguistic object to dialects and their distributions. He saw that drawing topographical boundaries for the sake of discussing language variations is as misleading as putting them into species and families. Already in his third inaugural lecture he has suggested studying la langue or EDL as a way of transcending strict localities and single points in time. He revealed to his audience that he preferred to study each dialect as well as language as an "intermediate link between its two neighbors to the East and the West" (Saussure 2006: 115-116). However, a more radical idea presented in his third course lecture is to look into the life of EDL which changes along with time but is not constricted within any space or direction (le développement libre; 1993: 21a-23a). He informed his students of the biological and evolutionary agenda he was considering for EDL:

To some extent one could also say that . . . la langue could be expanded to read the life of la langue ... that ... would contain things of importance for the characterization of la langue, and that these things are all part of a life, a biology. But there are other things that would not be included: among others, the whole logical side of la langue, involving invariables unaffected by time or geographical boundaries. . . Instead of geographical differences we have evolutionary differences. The evolution of la langue is one of the major concerns of linguistics. Geographical differentiation is only particular application of the facts of evolution; it has to be completely contained therein. (Saussure 1993: $11 \mathrm{a}, 22 \mathrm{a})$

First and foremost, such agenda elaborates on EDL in its abstract form: it discusses (1) why language users change their speeches as they constantly migrate from one place to another; (2) how linguists can still bring unity to 
their observations of these changes that approximately accord with inhabited regions. Unlike species that - under the naturalists' scope - are supposed to change their needs and develop new organic functions when moving from place to place, human consciousness is shifty wherever and however humans change their places of living. In emphasizing the autonomy of EDL that is distinguished from geographical localities, Saussure problematized the subtle scheme of time required for the observation of the life of EDL. Such a scheme goes beyond conventional notions of diachrony and history as it is about neither the programmed development nor the adaptation of species (1993: xxi). Second, in the context of species evolution, theoretical interests have been invested on isolated areas or places on the borders where new species are supposed to appear faster and more abundantly than in the mainlands. In developing EDL, Saussure deconstructed such distinctions by pointing out that both contiguity and separation of areas end up with the same result of differentiations of languages - it does not really take an island to prove the working of EDL (1993: 39a-40a; 1959: 210). Even when there is concentration on a certain geographical area, the purpose of assuming a continuum or aggregate of regions is not to prove the rate (or speed) of evolution. The aim is rather to illustrate the uneven distribution or propagation of EDL throughout that area (1993: 23a). The actual linguistic forces that crisscross an area are of more interest than the geographical area itself. Therefore, studying cases of extremely closed and provincial states where people adhere to a limited number of tongues cannot shed much light on the complexities of EDL. It is rather within areas where people are open to the intercourse of various tongues that we can avoid coming to a standstill and meanwhile expand our understanding of EDL in time (1959: 206-208). Saussure relates the force of intercourse to his scientific principle of unity as follows:

$[\mathrm{T}]$ he force of intercourse ... will be the force promoting linguistic unification (le principle unifiant pour la langue)... The influence of intercourse may appear in two forms: sometimes the new feature emerging at one point will be opposed and suppressed by the influence of intercourse. But you cannot say which among such innovations will be stifled. That is a process of conservation, of resistance. In other cases, an innovation introduced in one place is propagated, transmitted by this influence. Here again the result makes for unity, levelling, but by an active, positive process. It is this propagative form of the influence of intercourse that I propose to examine. (Saussure 1993: 33a34a)

His idea of intercourse enhances the fact that new features or innovations are composites (rather than modifications of previous ones) due to the coming together of different tongues and that there is no ladder or specific direction for their emergence and travelling: they emerge in tune with the conditions of EDL 
which are rather unpredictable as well. Furthermore, whether the conditions of EDL are favorable or not, innovations always keep their fundamental tone of life - they can hold their breath in harsh conditions and wait for the chances to resume their lives again. Just as much as geographical forces have shaped the appearances of the earth, the force of intercourse has been configuring EDL to such extent that there is no benefit of distinguishing the past from the present, the present from the future, this area from the next. What is observed about EDL here and now could have happened before and might still act out in the future. The notion of EDL thus brings forth an alternative concept to catastrophism - instead of presuming disparities between the past and the present, uniformitarianism not only appreciates the preservation of changes but also affirms the unity, continuity, and contiguity of processes in time (Gould 2007: 150-152). Saussure's discourse on uniformitarianism revised vulgar appropriations of Darwinism and geology that stick to the tree diagram and atlases showing natural languages, nations or races bordering against each other. In his third course lecture, he offered to visualize the intercourse of languages as a succession of waves and their overlaps in the form of loops:

A glance at a linguistic atlas will sometimes reveal two or three waves that almost coincide or even overlap in one zone. [Figure 4] [The invasion of a territory by a number of features may be compared to waves. These linguistic waves or innovations sometimes coincide over a certain stretch] [Figure 5]. The two points A and B, which are separated by such a zone, obviously have some divergences and constitute two rather clearly differentiated forms of speech. These concordances, instead of being partial, may characterize the whole perimeter of two or more zones [Figure 6]. A dialect is defined, roughly speaking, by a sufficient accumulation of such concordances. Their foundations are social, political, religious, etc., matters which do not concern us at the moment but which veil, without ever erasing completely, the basic and natural fact of

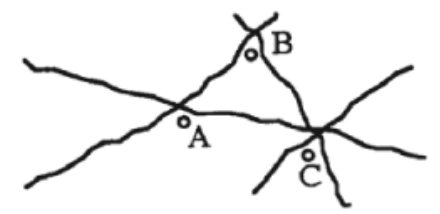

Figure 4. A zone crisscrossed by several waves (1993: 26)

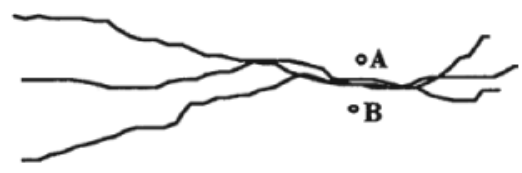

Figure 5. Several waves coincide over a certain stretch (1993: 27) 


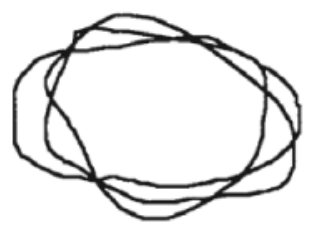

Figure 6. Loops showing the convergence and divergence of waves (1993: 28)

differentiation from zone to zone. (Saussure 1959: 202-203; lines within parentheses 1993: 27a)

These innovating waves vividly picture the propagation of EDL across zones and stretches of area - they are not adaptations to specific natural environments. Following the waves, we can find points of convergence that help refer to a couple of concordances (A, B, C, etc.). Although these concordances are segregated by the waves - they are by all means distinct from one another — they somehow share some features that make them look similar. Within the same zone of converged waves, the closer they are, the more features they share with each other; further away, these waves run parallel for a while, and it takes other conditions to find some other concordances, etc. Since humans have been migrating, EDL can find its life wherever and however - we never know how far away it will come to a stop. In addition, there are a host of other conditions outside linguistics - cultural and social situations, etc. - which participate in shaping the waves and their degrees of convergence. Most of all, the concept of unending flowing and converging waves reveals a hidden sense of evolution that is derived from mathematics and geometry - according to Saussure, innovations not only emerge from differentiations but also follow "the successive transformation of a curve by the alteration of conditions." It avoids the association with concepts like progressive development and perfected species that unfortunately have been mistaken as Darwin's genuine contribution. In the light of geobiology, EDL lives on "a high ratio of surface to volume" (two or more zones), which overcomes fixations within geographical, national or racial boundaries and assists in flowing, jumping, and travelling as much as can be (Gould 2007: 34-38; 197-198; Saussure 1959: 192-193; 204-205).

\section{Concluding remarks}

\subsection{Symbiogenesis in nature and culture}

We gain from Saussure's formulations of analogy and EDL a vista of the nature and intensity of evolution: his model is summarized from linguistic and cul- 
tural phenomena far and wide and - for its metacritical power accumulated from criticism of misappropriations of Darwinism - may well be considered as an alternative to Neo-Darwinian approaches in our time that base their studies of animals and humans on the tree of lineages, the classification of species and subspecies and, in particular, the determination of ontogeny, phylogeny, and reproduction by genes. Saussure's model illustrates evolution as a continuous process that alternates between convergence and divergence of (new) features and properties, and implies the fact that living beings of different ontogenetic and phylogenetic traits have been cross-fertilizing in accordance with multiple conditions in time. Neo-Darwinism has empirically traced the seat of the variation of species back to genes and chromosomes. However, it is more the differentiation and combination than the specific functions of genes that explicate the biological potentiality of merging and blending across species. Such happenings in the horizontal dimension have been underestimated in Neo-Darwinian approaches that focus on the heredity of genes and the ways it encodes or determines characteristics and behaviors in a linear fashion. My study proposes to take the diagram of general difference in Saussure's orangery manuscripts (Figure 2) as a normative framework to observe symbiogenesis in order to achieve greater truths about nature and culture. This framework enables us to perceive that both ontogeny and phylogeny have been constantly restructuring - in the words of Stephen Jay Gould, it takes "multivariate analysis" to go beyond taxonomy, isolated traits, and gene determinism so as to discover inspiring patterns of (new) life based on the observation of a composite of factors or conditions simultaneously.

\subsection{Theoretical framework(s) of biosemiotics}

In his retrospective review of Thomas A. Sebeok's career, John Deely highlights the fact that his master's thinking about linguistics and biology in parallel became a converged and enlarging theme after the coinage of key terms like zoösemiotics (in 1963) and anthroposemiotics (in 1968) — both terms were aimed at analyzing species-specific communications among animals and humans respectively (Deely 2004: 2-5). Meanwhile, Sebeok came to read the original first version of Jakob von Uexküll's Theoretische Biologie (1920), which led him to widen his scope of semiotics in the rather encompassing domain of biosemiotics (Sebeok 1998: 32). In the 1970s, he came up with a preliminary definition of biosemiotics as follows:

It seems likely that a full-fledged synthesis will be achieved before long, offering both a new paradigm and a methodology for the comparative analysis of semiosis in its full diversity, ranging from the two vast linked polymer languages [genetic codes] at one 
end of the scale to the thousands of natural languages at the other, with a host of singular information coding and transmission devices, inside and outside the body of every organism, in between. Semiosis, independent of form or substance, is thus seen as a universal, criterial property of animate existence. (Sebeok 1973: 1189; 1998: 32; Krampen et al. 1987: 214)

His idea was paraphrased and included in a glossary entry, defining semiosis as follows: "Also, semiose [semiosis] is understood in BIOSEMIOTICS as a transfer of signs, e.g., an INTERPRETATION through which signs are replicated and further developed. Examples of such dynamic reproductions extend, for Sebeok, from the genetic CODE through all stages of transmission of information up to human speech, action and thought" (Krampen et al. 1987: 244245).

As a new approach, envisaged to shed light on the animate, biosemiotics synthesizes the studies of animals with those of human beings, the coding and transmission of signals inside organic bodies with those outside, and the symbolic codes used among scientists with the communication of languages in our daily lives. However, without making any clear distinctions between these diversities, biosemiotics has taken all physical and biological processes as a matter of semiosis and semiotics. Genetic codes that define the biological properties of living beings are - according to Darwinian and Neo-Darwinian conceptualizations - rigid and not subject to be modified in the regular process of reproduction and transmission. They are quasi-automatic and selfsufficient that each code can find a stereotypical counterpart, just like the way that a key fits a keyhole. The logic in an enclosed genetic system is to obey the necessities and to bridge the equivalences among codes. Nevertheless, the biological nature of consciousness- and language-based semiotics is about making options from available codes - a subject picks up a favored code, interprets, and complicates the meanings of the code as infinitely as possible.

Furthermore, in the light of Peirce, semiosis is a precondition of semiotics, and it is a growing and enlarging circle of interpretation that gradually deviates from an original sign and involves other objects in the world. The opaqueness in such a process lies in the fact that it is difficult to tell how the interpreting subject is going to shift his frameworks of references. Semiotics in this sense is not far-fetched from Saussure's idea of consciousness and EDL, the nature of which is supposed to be making comparisons and associations as well. Even though Peirce and Saussure theorize consciousness as a process of internal mental reconstruction, they would agree that outsiders, heterogeneous beings, or individuals of different kinds are required in appreciating the ambiguity and flexibility of semiotic processes. Unfortunately, Sebeok, in his preliminary definition imposes the kind of opaque, unfaithful, and non-transparent quality of semiosis upon the presumably stable and transparent quality of biological 
codes and processes in nature. The eclectic attitude in Sebeok of bringing these two conflicting states under the same paradigm of biosemiotics has committed the fallacy of a confused epistemology — biosemiotics is torn between approaches in natural sciences, which practice more or less Darwinian principles, and those in cultural and social semiotics that actually prefer to avoid such doctrines. We should draw on Saussure's underestimated discourse of EDL and his evolutionary epistemology if we take it a task to unify diverse approaches that have been made available to biosemiotics.

\section{Notes}

1. We should pay attention to the fact that Saussure's explication of analogy is included in the section on "diachronic linguistics" in CGL.

2. Oxford English Dictionary, $2^{\text {nd }}$ edn., s.v. "evolution."

\section{References}

Alinei, Mario. 2006. Darwinism, traditional linguistics, and the new Palaeolithic theory of language evolution. In Nathalie Gontier, Jean Paul Van Bendegem \& Diederik Aerts (eds.), Evolutionary epistemology, language, and culture: A non-adaptationist, systems theoretical approach, 121-147. Dordrecht: Springer.

Amsterdamska, Olga. 1987. Schools of thought: The development of linguistics from Bopp to Saussure. Dordrecht: D. Reidel.

Auroux, Sylvain. 2007. Introduction: Le paradigme naturaliste. Histoire Épistémologie Langage 29(2). 5-15.

Barbieri, Marcello. 2003. The organic codes: An introduction to semantic biology. Cambridge \& New York: Cambridge University Press.

Barbieri, Marcello. 2008. Biosemiotics: A new understanding of life. Naturwissenschaften 95(7). $577-599$.

Bouissac, Paul. 2004. Saussure's legacy in semiotics. In Carol Sanders (ed.), The Cambridge companion to Saussure, 240-260. Cambridge \& New York: Cambridge University Press.

Bouquet, Simon. 1997. Introductions à la lecture de Saussure. Paris: Editions Payot \& Rivages.

Chebanov, Sergey V. 1998. Totality of semiosphere. Sign Systems Studies 26. 417-424.

Da Camara, Joao Bettencourt. 1995. Saussure, chess, and time: The role of an analogy in a scientific revolution. Lisbon: Universidade Tecnica De Lisboa.

Danesi, Marcel. 2004. A basic course in anthropological linguistics. Toronto: Canadian Scholars' Press.

Deely, John. 2004. Thomas Albert Sebeok, "Biologist Manqué.” Unpublished paper presented at the Congress of International Association for Semiotic Studies in Lyon.

Engler, Rudolf. 2004. The making of the Cours de linguistique générale. In Carol Sanders (ed.), The Cambridge companion to Saussure, 47-58. Cambridge \& New York: Cambridge University Press.

Gontier, Nathalie. 2006. Evolutionary epistemology and the origin and evolution of language: Taking symbiogenesis seriously. In Nathalie Gontier, Jean Paul Van Bendegem \& Diederik Aerts 
(eds.), Evolutionary epistemology, language, and culture: A non-adaptationist, systems theoretical approach, 195-226. Dordrecht: Springer.

Gould, Stephen Jay. 2007 [1977]. Ever since Darwin: Reflections on natural history. New York \& London: W. W. Norton.

Harris, Roy. 1993. Saussure and linguistic geography. Language Sciences 15(1). 1-14.

Harris, Roy. 2002. Ferdinand de Saussure, "Écrits de linguistique générale." Times Literary Supplement 5182. 30 .

Hoffmeyer, Jesper. 1996. Signs of meaning in the universe, Barbara J. Haveland (trans.). Bloomington: Indiana University Press.

Hurford, James R. 1992. An approach to the phylogeny of the language faculty. In J. A. Hawkins \& M. Gell-Mann (eds.), The evolution of human languages (SFI Studies in the Sciences of Complexity 11), 273-303. Redwood City, CA: Addison-Wesley.

Hurford, James R. 2007. Why communicate? Squaring with evolutionary theory. In The origins of meaning: Language in the light of evolution, 243-306. New York: Oxford University Press.

Itkonen, Esa. 2005. Analogy as structure and process: Approaches in linguistics, cognitive psychology, and philosophy of science. Amsterdam: John Benjamins.

Jakobson, Roman. 1990 [1966]. Quest for the essence of language. In Linda R. Waugh \& Monique Monville-Burston (eds.), On language, 407-421. Cambridge, MA \& London: Harvard University Press.

Katz, Gregory. 2008. The hypothesis of a genetic protolanguage: An epistemological investigation. Biosemiotics 1. 57-73.

Klippi, Carita. 2007. La première biolinguistique. Histoire Épistémologie Langage 29(2). 17-40.

Krampen, Martin, Klaus Oehler, Roland Posner, Thomas A. Sebeok, and Thure von Uexküll (eds.) 1987. Classics of semiotics. New York: Plenum Press.

Kull, Kalevi. 1998. Semiotic ecology: Different natures in the semiosphere. Sign Systems Studies 26. 344-371.

Kull, Kalevi. 2003. Thomas A. Sebeok and biology: Building biosemiotics. Cybernetics and Human Knowing 10(1). 47-60.

McCauley, Robert N. 2007. Enriching philosophical models of cross-scientific relations: Incorporating diachronic theories. In Maurice Schouten \& Huib Looren de Jong (eds.), The matter of the mind: Philosophical essays on psychology, neuroscience, and reduction, 199-223. Oxford: Blackwell.

Nerlich, Brigitte. 1989. The evolution of the concept of "linguistic evolution" in the nineteenth and twentieth centuries. Lingua 77(2). 101-112.

Nöth, Winfried. 1998. Ecosemiotics. Sign Systems Studies 26. 332-343.

Saussure, Ferdinand de. 1959. Course in general linguistics, Charles Bally, Albert Sechehaye \& Albert Riedlinger (eds.), Wade Baskin (trans.). New York: McGraw-Hill.

Saussure, Ferdinand de. 1967. Cours de linguistique générale, vols. 1-2, R. Engler (ed.). Wiesbaden: Otto Harrassowitz.

Saussure, Ferdinand de. 1968. Cours de linguistique générale, vol. 3, R. Engler (ed.). Wiesbaden: Otto Harrassowitz.

Saussure, Ferdinand de. 1993. Troisième cours de linguistique générale (1910-1911) d'après les cahiers d'Émile Constantin / Saussure's third course of lectures on general linguistics (1910-1911) from the notebooks of Émile Constantin, E. Komatsu (ed.), R. Harris (trans.). Oxford: Pergamon.

Saussure, Ferdinand de. 1996. Premier cours de linguistique générale (1907) d'après les cahiers d'Albert Riedlinger / Saussure's first course of lectures on general linguistics (1907) from the notebooks of Albert Riedlinger, E. Komatsu (ed.), G. Wolf (trans.). Oxford: Pergamon.

Saussure, Ferdinand de. 2002. Écrits de linguistique générale, Simon Bouquet \& Rudolf Engler (eds.). Paris: Gallimard. 
Saussure, Ferdinand de. 2006. Writings in general linguistics. Oxford \& New York: Oxford University Press.

Schleicher, August. 1983. The Darwinian theory and the science of language, A. V. W. Bikkers (trans.). In Konrad Koerner (ed.), Linguistics and evolution theory: Three essays by August Schleicher, Ernst Haeckel, and Wilhelm Bleek, 1-72. Amsterdam: John Benjamins.

Sebeok, Thomas A. 1973. Between animal and animal. Times Literary Supplement 3734. 11871189.

Sebeok, Thomas A. 1976. Contributions to the doctrine of signs. Bloomington: Indiana University Press.

Sebeok, Thomas A. 1998. The Estonian connection. Sign Systems Studies 26. 20-41.

Jui-pi Chien (b. 1973) is an assistant professor at National Taiwan University $<$ jpchien@ntu.edu. tw $>$. Her research interests include semiotics, comparative literature, comparative arts, and the history and philosophy of science. Her publications include "From animals to humans: Uexküll's Umwelt as read by Lacan and Canguilhem" (2006); "Of animals and men: A study of Umwelt in Uexküll, Cassirer, and Heidegger" (2006); "Umwelt, milieu(x), and environment: A survey of cross-cultural concept mutations" (2007); and "The French reception of Jakob von Uexküll's Umwelt: A regional variation of global semiotics" (2007). 